\title{
Regional Contributions to Poststroke Disability in Endovascular Therapy
}

\author{
Sunil A. Sheth ${ }^{a}$ Konark Malhotra $^{b}$ David S. Liebeskind ${ }^{c}$ \\ Conrad W. Liang ${ }^{d}$ Albert J. Yoo ${ }^{e}$ Reza Jahan $^{f}$ Raul G. Nogueirag \\ Vitor Pereirah $^{h}$ Jan Gralla ${ }^{i}$ Greg Albers ${ }^{j}$ Mayank Goyalk \\ Jeffrey L. Saver ${ }^{c}$ for the SWIFT/STAR/SWIFT PRIME Investigators \\ a Department of Neurology, UT Health McGovern School of Medicine, Houston, TX, USA; \\ ${ }^{b}$ Department of Neurology, Charleston Area Medical Center, West Virginia University, \\ Charleston, WV, USA; ' ${ }^{\circ}$ Department of Neurology and Stroke Center, University of California, \\ Los Angeles, CA, USA; d Department of Neurosurgery, Kaiser Permanente, Fontana, CA,

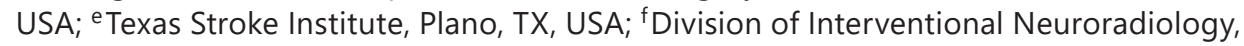 \\ University of California, Los Angeles, CA, USA; ${ }^{9}$ Department of Neurology, Emory \\ University, Atlanta, GA, USA; h Divisions of Neuroradiology and Neurosurgery, Toronto \\ Western Hospital, Toronto, ON, Canada; ${ }^{i}$ Department of Diagnostic and Interventional \\ Neuroradiology, Inselspital, University of Bern, Bern, Switzerland; jDepartment of \\ Neurology, Stanford University, Stanford, CA, USA; ${ }^{k}$ Diagnostic and Interventional \\ Neuroradiology, University of Calgary, Calgary, AB, Canada
}

\section{Keywords}

ASPECTS $\cdot$ Eloquence $\cdot$ Large vessel occlusion $\cdot$ Neuroimaging $\cdot$ Stroke

\begin{abstract}
Background and Purpose: The relative contribution of each Alberta Stroke Program Early CT Score (ASPECTS) region to poststroke disability likely varies across regions. Determining the relative weights of each ASPECTS region may improve patient selection for endovascular stroke therapy (EST). Methods: In the combined Solitaire Flow Restoration with the Intention for Thrombectomy (SWIFT), Solitaire Flow Restoration Thrombectomy for Acute Revascularization (STAR), and Solitaire Flow Restoration with the Intention for Thrombectomy as Primary Endovascular Treatment (SWIFT PRIME) databases, we identified patients treated with the Solitaire stent retriever. Using 24-h CT scan, a multivariate ordinal regression was used to determine the relative contribution of each ASPECTS region to clinical outcome separately in each hemisphere. The coefficients from the regression were used to create a weighted ASPECTS (WASPECTS), which was compared with the original ASPECTS to predict 90-day modified Rankin Scale disability outcomes in an independent validation cohort. Results: Among 342 patients treated with EST, the average age was 67 years, $57 \%$ were female, and the me-
\end{abstract}


dian National Institutes of Health Stroke Scale (NIHSS) score was 17 (IQR 13-20). The median ASPECTS at presentation was 8 (IQR 7-10). The most commonly involved ASPECTS regions on 24-h CT were the lentiform nuclei (70\%), insula (55\%), and caudate (52\%). In multivariate analysis, preservation of $M 6(\beta=9.7)$ and $M 4(\beta=4.4)$ regions in the right hemisphere was most strongly predictive of good outcome. For the left hemisphere, M6 ( $\beta=5.5)$, M5 ( $\beta=4.1$ ), and M3 $(\beta=3.1)$ generated the greatest parameter estimates, though they did not reach statistical significance. A wASPECTS incorporating all 20 parameter estimates resulted in improved discrimination against the original ASPECTS in the independent cohort (C-statistic 0.78 vs. 0.67, right hemisphere). Conclusions: For both right and left hemisphere, preservation of the high cortical regions was more strongly associated with improved outcomes compared to the deep regions. Our findings support taking into consideration the location and relative weightings of the involved ASPECTS regions when evaluating a patient for EST.

(c) 2018 S. Karger AG, Basel

\section{Introduction}

Multiple trials of endovascular stroke therapy (EST) in 2015 established this treatment as a major advance in acute ischemic stroke care [1-5]. The results of these trials were in stark contrast to a series of negative studies released in 2013 [6-8]. This improvement was due in large part to the improved efficacy of stent retrievers as well as advances in patient selection, such as use of the Alberta Stroke Program Early CT Score (ASPECTS) to quantify early ischemic injury [3-5]. ASPECTS is 10-point scale that divides and assigns 1 point to 10 anterior circulation regions in each hemisphere: three deep regions (lentiform nuclei, caudate, internal capsule), four cortical regions at the level of the basal ganglia (M1, M2, M3, insula), and three cortical regions above the basal ganglia level (M4, M5, M6) [9]. In many of these landmark trials an ASPECTS $\geq 6$ was required for inclusion, and as a result the American Heart Association guidelines that soon followed the release of these studies adopted this criterion [10]. While this criterion helped contribute to the large treatment effect sizes of the trials, it opens up questions about why not all patients with favorable ASPECTS do well in spite of rapid reperfusion, and whether patients with lower ASPECTS may still benefit from therapy [11].

Previous studies have demonstrated that infarct location, in addition to size, determines clinical outcomes [12]. Further, functional recovery after stroke is highly correlated with the type and location of injured brain tissue [13-16]. As such, while ASPECTS assigns each of its components the same value, it is unlikely that they are in fact contributing to disability outcomes equivalently.

The key question in the neuroimaging evaluation of a patient presenting with large vessel occlusion is whether the existing infarct precludes any reasonable chance of benefit EST may provide. To answer this question, a more accurate measurement may be one that takes into account not only the infarct volume, but also the relative eloquence of the affected regions. To date, the relative contribution of each ASPECTS region to poststroke disability remains poorly characterized. In this study, we derived regional weightings of ASPECTS components and then assessed whether this weighted model improves clinical outcome prediction.

\section{Methods}

Study Design and Participants

We performed a pooled, post hoc, exploratory analysis of the Solitaire Flow Restoration with the Intention for Thrombectomy (SWIFT) [17], Solitaire Flow Restoration Thrombectomy for Acute Revascularization (STAR) [18], and Solitaire Flow Restoration with the Intention for Thrombectomy as Primary Endo- 
Sheth et al.: Weighted ASPECTS for Endovascular Stroke Therapy Selection

vascular Treatment (SWIFT PRIME) [3] clinical trials. The study designs have been described in detail previously $[3,17,18]$. STAR was a prospective, single-arm, multicenter study conducted from January 1, 2010 through December 31, 2012 in which all acute ischemic stroke patients with anterior circulation large vessel occlusion were treated with the Solitaire stent retriever (Medtronic, Dublin, Ireland).SWIFT was arandomized clinical trial conducted from January 1, 2010 through December 31, 2011 that included acute ischemic stroke patients with anterior circulation large vessel occlusion confirmed on angiography. The patients were allocated either to the Solitaire stent retriever or the Merci device (Concentric Medical, Mountain View, CA, USA). SWIFT patients in the Solitaire roll-in phase were included. In both STAR and SWIFT, patients were included only if EST was feasible within $8 \mathrm{~h}$ of symptom onset. Intravenous thrombolysis was recommended to eligible patients within $4.5 \mathrm{~h}$ of symptom onset without any contraindications. In SWIFT PRIME, acute ischemic stroke patients with confirmed anterior circulation large vessel occlusion were randomized between intravenous tissue plasminogen activator followed by EST with a stent retriever and intravenous tissue plasminogen activator alone. The trial ran from December 2012 until November 2014. The clinical endpoints in all trials included blinded assessment of 90-day modified Rankin Scale (mRS) score. SWIFT was conducted in the United States, STAR in Europe, Canada, and Australia, and SWIFT PRIME in the United States and Europe. For all the trials, independent core laboratories and clinical event committees adjudicated imaging and clinical outcome data. All patients gave their informed consent, and the study protocol was approved by the institutional review board.

Patients were included in our study if they underwent EST with the Solitaire device for either internal carotid artery (ICA) or middle cerebral artery occlusion, had suitable follow-up 24-h CT imaging, and did not have symptomatic intracerebral hemorrhage. Symptomatic intracerebral hemorrhage was defined as any hemorrhage within $24 \mathrm{~h}$ associated with an increase of $\geq 4$ points on the National Institutes of Health Stroke Scale (NIHSS) or that resulted in death.

\section{Imaging Review and Analysis}

The details of imaging analysis for each study have been described earlier. All patients underwent 24-h imaging studies. For consistency, only patients with 24-h CT scans were included, and all ASPECTS scoring was performed off CT imaging. ASPECTS on 24-h CT was evaluated in total as well as by subcomponents: lentiform nuclei, caudate, internal capsule, insula, anterior inferior frontal lobe (M1), temporal lobe (M2), inferior parietal and posterior temporal lobe (M3), superior anterior frontal lobe (M4), precentral and superior frontal lobe (M5), and superior parietal lobe (M6).

\section{EST Procedure}

The EST procedures of SWIFT, STAR, and SWIFT PRIME have been discussed previously $[3,17,18]$. The use of a balloon guide was mandatory in the SWIFT and STAR studies whereas it was optional in SWIFT PRIME. The study protocols allowed up to three passes with stent retrievers; performance of additional passes at the discretion of the interventionalist was considered as a protocol violation.

\section{Statistical Analysis}

Categorical variables were compared between groups using Fisher's exact test, and continuous variables were evaluated with Student's $t$ test or the Wilcoxon rank sum test (when median and IQRs are reported). A two-sided $p$ value $<0.05$ was considered significant and all estimates were calculated for $95 \%$ CI. A $p$ value $<0.1$ was considered as a trend towards significance. All statistical analyses were conducted in SAS, version 9.3 (SAS, Cary, NC, USA).

The study population was then randomly divided into derivation $(2 / 3)$ and validation $(1 / 3)$ cohorts, and weightings for each ASPECTS subregion on the 24-h CT were generated in the derivation cohort by ordinal logistic regression against the 90-day mRS score, adjusted for age, baseline NIHSS score, and target occlusion location. This analysis was performed separately for the right and left hemispheres. In order to minimize the impact of final infarct volume on functional outcomes, each subcomponentscore was normalized against the total number of involved regions prior to the regression. This analysis was also performed against day 7-10 or discharge NIHSS score.

A weighted ASPECTS (WASPECTS) was created by using the parameter estimates from the regressions for the right and left hemispheres as each subcomponent's new ASPECTS value. We then compared the discriminative ability of the wASPECTS against original ASPECTS for predicting mRS score $0-2$ versus mRS score 3-6 at 90 days by receiver operating characteristic curves and their corresponding C-statistics. These comparisons were made first in the derivation cohort and then in the independent validation cohort. 
Table 1. Baseline characteristics of the analyzed SWIFT/STAR/SWIFT PRIME cohort

\begin{tabular}{|c|c|c|c|c|c|}
\hline Patient characteristic & $\begin{array}{l}\text { All patients } \\
(n=342)\end{array}$ & $\begin{array}{l}\text { ASPECTS } 9-10 \\
(n=69)\end{array}$ & $\begin{array}{l}\text { ASPECTS 6-8 } \\
(n=166)\end{array}$ & $\begin{array}{l}\text { ASPECTS } 0-5 \\
(n=107)\end{array}$ & $\begin{array}{l}p \\
\text { value }^{1}\end{array}$ \\
\hline Age & $67(13)$ & $72(11)$ & $67(13)$ & $65(13)$ & 0.004 \\
\hline Female & $57 \%$ & $64 \%$ & $61 \%$ & $47 \%$ & 0.026 \\
\hline Presentation NIHSS score & $17(13-20)$ & $16(11-18)$ & $16(12-19)$ & $18(15-21)$ & $<0.001$ \\
\hline Left hemisphere involvement & $48 \%$ & $55 \%$ & $48 \%$ & $42 \%$ & 0.236 \\
\hline \multicolumn{6}{|l|}{ Medical history } \\
\hline Atrial fibrillation & $38 \%$ & $51 \%$ & $38 \%$ & $30 \%$ & 0.021 \\
\hline Hypertension & $65 \%$ & $61 \%$ & $69 \%$ & $60 \%$ & 0.214 \\
\hline Diabetes & $16 \%$ & $17 \%$ & $13 \%$ & $21 \%$ & 0.149 \\
\hline Smoking & $17 \%$ & $13 \%$ & $17 \%$ & $21 \%$ & 0.442 \\
\hline Prior stroke/transient ischemic attack & $16 \%$ & $16 \%$ & $13 \%$ & $21 \%$ & 0.214 \\
\hline Prestroke mRS score & $0.4(0.8)$ & $0.3(0.7)$ & $0.4(0.8)$ & $0.4(0.8)$ & 0.818 \\
\hline Target occlusion location & & & & & 0.008 \\
\hline ICA & $13 \%$ & $12 \%$ & $11 \%$ & $16 \%$ & \\
\hline M1 & $76 \%$ & $64 \%$ & $80 \%$ & $78 \%$ & \\
\hline M2 & $11 \%$ & $23 \%$ & $8 \%$ & $6 \%$ & \\
\hline M3 & $1 \%$ & $1 \%$ & $1 \%$ & $1 \%$ & \\
\hline TICI $2 b / 3$ & $85 \%$ & $96 \%$ & $90 \%$ & $71 \%$ & $<0.001$ \\
\hline Presentation ASPECTS & $8.0(7.0-10.0)$ & $10.0(9.0-10.0)$ & $8.0(8.0-10.0)$ & $7.0(5.0-8.0)$ & $<0.001$ \\
\hline Receipt of intravenous t-PA & $73 \%$ & $65 \%$ & $75 \%$ & $74 \%$ & 0.324 \\
\hline Baseline serum glucose & $128(55)$ & $119(37)$ & $126(58)$ & $135(57)$ & 0.160 \\
\hline Time from hospital arrival to groin puncture & $84(55-118)$ & $82(54-115)$ & $88(59-125)$ & $82(51-116)$ & 0.229 \\
\hline Time from onset to reperfusion & 301 (99) & $289(94)$ & $282(94)$ & $340(100)$ & $<0.001$ \\
\hline
\end{tabular}

Values are presented as mean (standard deviation), median (IQR), or percent. ASPECTS, Alberta Stroke Program Early CT Score; ICA, internal carotid artery; M1, anterior inferior frontal lobe; M2, temporal lobe; M3, inferior parietal and posterior temporal lobe; mRS, modified Rankin Scale; NIHSS, National Institutes of Health Stroke Scale; STAR, Solitaire Flow Restoration Thrombectomy for Acute Revascularization; SWIFT PRIME, Solitaire Flow Restoration with the Intention for Thrombectomy as Primary Endovascular Treatment; SWIFT, Solitaire Flow Restoration with the Intention for Thrombectomy; t-PA, tissue plasminogen activator. ${ }^{1} p$ values for continuous variables calculated by $t$ test (when mean is reported) or Wilcoxon test (when median is reported); $p$ values for discrete variables calculated by Fisher's exact test.

\section{Results}

Among the 542 patients that were enrolled in SWIFT $(n=144)$, STAR $(n=202)$, and SWIFT PRIME $(n=196), 342$ patients met the inclusion criteria and were included in the study. In this cohort, the mean age was $67 \pm 13$ years, $57 \%$ were female, and the median NIHSS score was 17 (IQR 13-20), as shown in Table 1. Median presentation CT-ASPECTS was 8.0 (IQR 7-10), the mean time from symptom onset to reperfusion was $301 \pm 99 \mathrm{~min}$, and $85 \%$ of the patients achieved TICI $2 \mathrm{~b} / 3$ reperfusion. On 24-h CT, ASPECTS was 9-10 in 69 (20.2\%) patients, 6-8 in 166 (48.5\%) patients, and 0-5 in 107 (31.3\%) patients. Compared to patients with 24-h ASPECTS 9-10, those with ASPECTS 0-5 had higher presentation NIHSS score (16 vs. 18), higher frequency of ICA occlusion (12 vs. 16\%), lower rates of TICI $2 \mathrm{~b} / 3$ reperfusion ( 96 vs. 71\%), lower presentation ASPECTS (10 vs. 7), longer onset to reperfusion time (289 vs. $340 \mathrm{~min}$ ), and were less frequently female (64 vs. $47 \%$ ).

On 24-h CT, the most commonly involved ASPECTS regions were the lentiform nuclei (70\%), insula (55\%), and caudate (52\%). The frequency and distribution of individual subcomponents of 24-h ASPECTS are shown in Figure 1. The most common ASPECTS was 8, and the majority of patients had ASPECTS $\geq 5$, though the entire range of ASPECTS from 0 to 10 was represented. Similarly, although caudate, lentiform nuclei, and insula were the most 


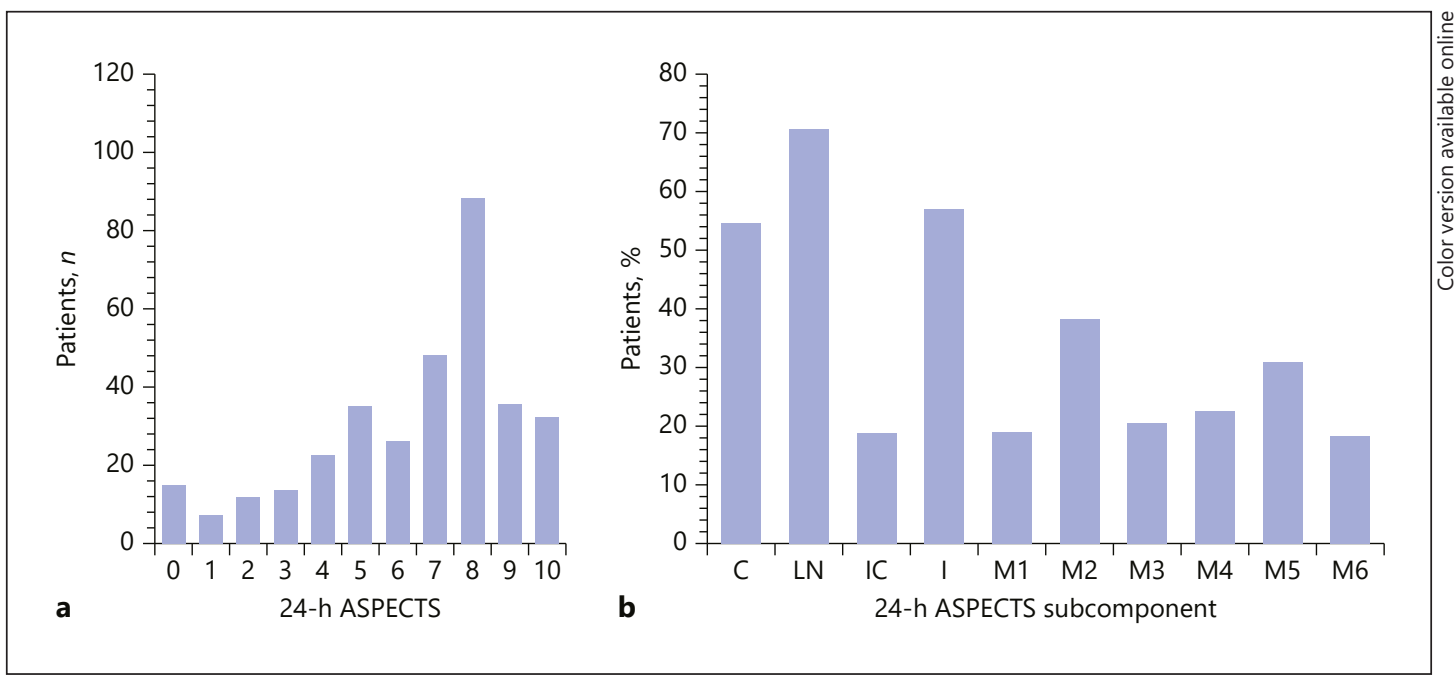

Fig. 1. Histogram of the frequency (a) and distribution (b) of ASPECTS components on 24-h CT in this analysis. ASPECTS, Alberta Stroke Program Early CT Score; C, caudate; LN, lentiform nuclei; IC, internal capsule; I, insula; M1, anterior inferior frontal lobe; M2, temporal lobe; M3, inferior parietal and posterior temporal lobe; M4, superior anterior frontal lobe; M5, precentral and superior frontal lobe; M6, superior parietal lobe.

commonly involved regions, each ASPECTS subcomponent was involved in at least $15 \%$ of the entire population.

In the derivation cohort, the relative contribution of each ASPECTS subcomponent to the 90-day ordinal mRS score was assessed. In the right hemisphere (Table 2), involvement of the M4 and M6 regions was significantly associated with higher mRS score. Overall, the ORs for the cortical regions (M1-M6) were greater than those for the deep regions (caudate, lentiform nuclei, and internal capsule), with the notable exception of the M3 region. For the left hemisphere (Table 2), none of the regions reached statistical significance, though in contrast to the right hemisphere, involvement of the $\mathrm{M} 3$ region showed a trend towards significant increase in mRS. Similar to the right hemisphere, involvement of the M5 and M6 regions showed association with higher mRS score. Again, the overall contribution of the deep regions was less than that of the cortical regions. These data are represented in Figure 2.

This analysis was then repeated with the same derivation cohort using day 7-10 or discharge NIHSS score as the outcome measure. The results of these analyses are presented in Figure 3. Again, cortical regions were found to have greater influence on ordinal day 7-10 or discharge NIHSS score compared to deep regions. In addition, similar differences in regional contributions were observed from the right to the left hemisphere, and specifically, the M3 region had a higher parameter estimate in the left as compared to the right hemisphere.

The parameter estimates in Table 2 were then used to create a wASPECTS. All regions were included regardless of $p$ value, and the model was evaluated for predicting dichotomized mRS score $0-2$ versus mRS score 3-6 at 90 days using receiver operating characteristic curve analysis. The results of this analysis in the derivation arm are demonstrated in online supplementary Figure 1 (see www.karger.com/doi/10.1159/000492400 for all online suppl. material). Compared to the original ASPECTS, both right and left hemisphere wASPECTS demonstrated improved discrimination in the derivation arm as shown in Table 3 as well as online supplementary Figures 2 and 3 (C-statistic 0.67 vs. 0.74 for right hemisphere and 0.78 for left hemisphere). This model was then tested independently in the validation cohort as shown in Table 3. The wASPECTS for right hemisphere demon- 


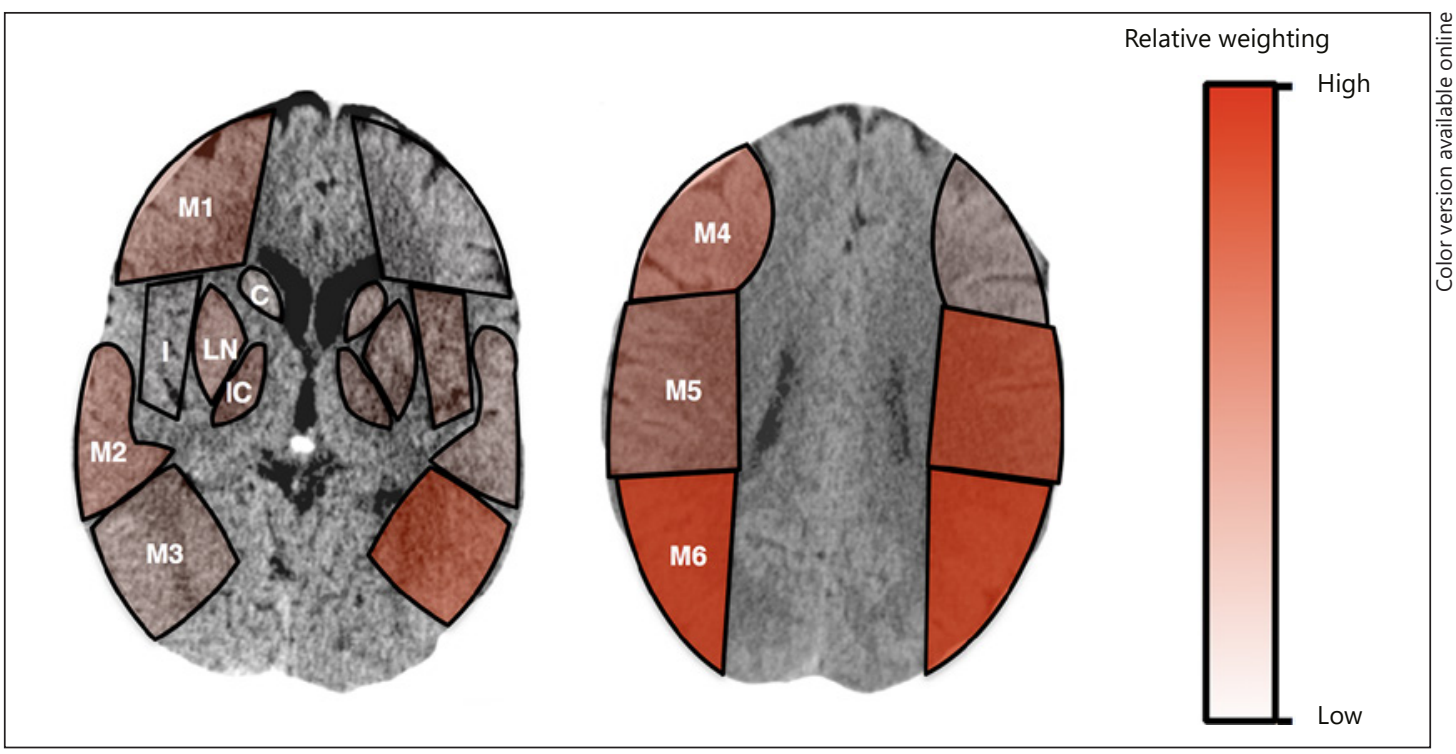

Fig. 2. Visual representation of ASPECTS subregion weighting against ordinal 90-day mRS outcomes. Different color variations from light to dark depict corresponding relative weights contributed by each subregion. ASPECTS, Alberta Stroke Program Early CT Score; C, caudate; I, insula; IC, internal capsule; LN, lentiform nuclei; M1, anterior inferior frontal lobe; M2, temporal lobe; M3, inferior parietal and posterior temporal lobe; M4, superior anterior frontal lobe; M5, precentral and superior frontal lobe; M6, superior parietal lobe; mRS, modified Rankin Scale.

Table 2. Ordinal logistic regression of ASPECTS on 24-h CT scan for patients with right and left hemisphere involvement against 90-day mRS score in the "derivation" cohort

\begin{tabular}{lrl}
\hline ASPECTS subcomponent & Estimate & $p$ value \\
\hline Right hemisphere & & \\
Caudate & -0.1318 & 0.908 \\
Lentiform nucleus & 1.5901 & 0.080 \\
Internal capsule & 1.4291 & 0.322 \\
Insula & -0.8191 & 0.441 \\
M1 & 2.3523 & 0.436 \\
M2 & 2.6144 & 0.168 \\
M3 & 0.8730 & 0.503 \\
M4 & 4.4199 & 0.043 \\
M5 & 3.2771 & 0.112 \\
M6 & 9.6624 & 0.002 \\
\hline Left hemisphere & & \\
Caudate & -0.00918 & 0.993 \\
Lenticular nucleus & 0.0181 & 0.984 \\
Internal capsule & -0.0656 & 0.976 \\
Insula & 0.1563 & 0.883 \\
M1 & -0.9795 & 0.546 \\
M2 & -0.0175 & 0.994 \\
M3 & 3.1379 & 0.073 \\
M4 & -0.0882 & 0.963 \\
M5 & 4.0935 & 0.203 \\
M6 & 5.4802 & 0.147 \\
\hline
\end{tabular}

ASPECTS, Alberta Stroke Program Early CT Score; M1, anterior inferior frontal lobe; M2, temporal lobe; M3, inferior parietal and posterior temporal lobe; M4, superior anterior frontal lobe; M5, precentral and superior frontal lobe; M6, superior parietal lobe; mRS, modified Rankin Scale. 


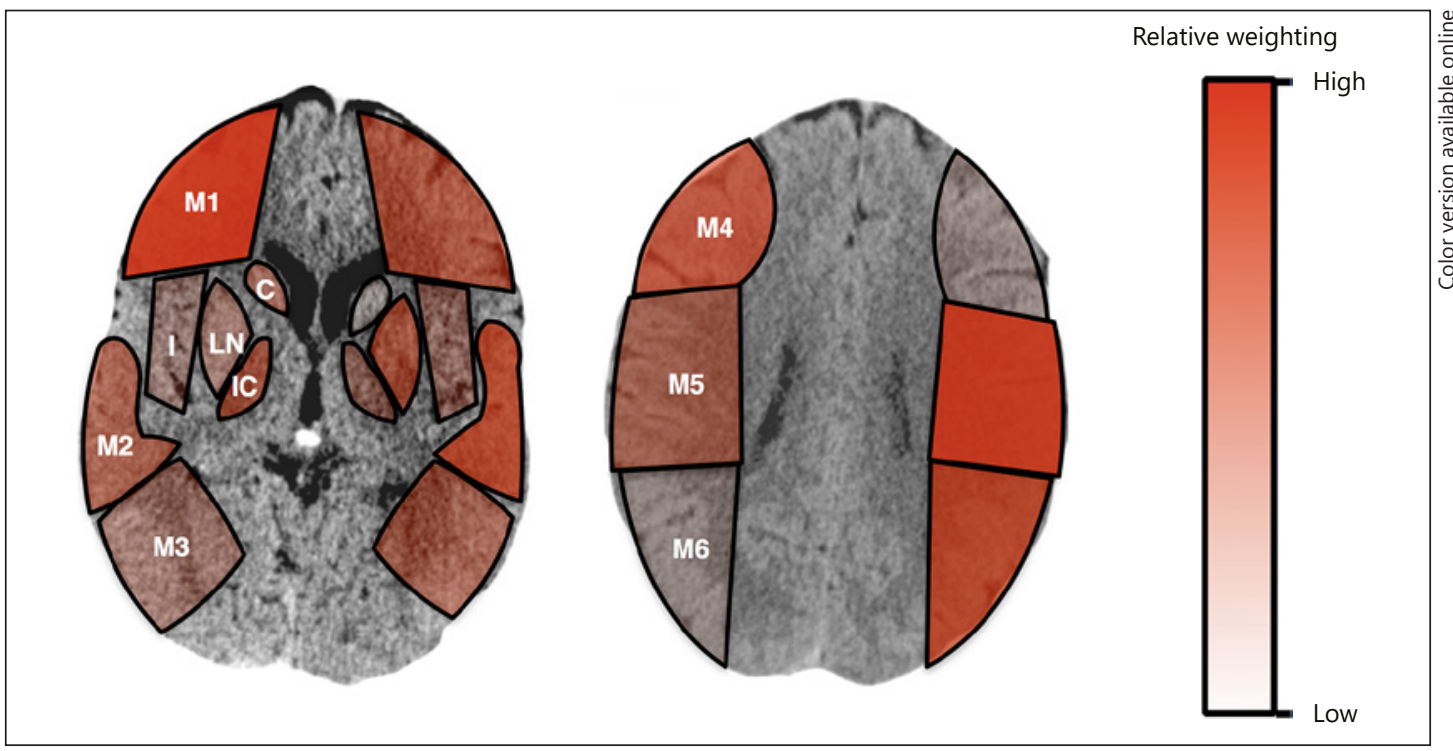

Fig. 3. Visual representation of ASPECTS subregion weighting against ordinal day 7-10 or discharge NIHSS score. Different color variations from light to dark depict corresponding relative weights contributed by each subregion. ASPECTS, Alberta Stroke Program Early CT Score; C, caudate; I, insula; IC, internal capsule; LN, lentiform nuclei; M1, anterior inferior frontal lobe; M2, temporal lobe; M3, inferior parietal and posterior temporal lobe; M4, superior anterior frontal lobe; M5, precentral and superior frontal lobe; M6, superior parietal lobe; NIHSS, National Institutes of Health Stroke Scale.

Table 3. ASPECTS subregion weighting against 90-day mRS score

\begin{tabular}{ll}
\hline Model name & C-statistic \\
\hline Original ASPECTS (derivation) & 0.67 \\
EL-ASPECTS right hemisphere (derivation) & 0.74 \\
EL-ASPECTS left hemisphere (derivation) & 0.78 \\
EL-ASPECTS right hemisphere (validation) & 0.78 \\
EL-ASPECTS left hemisphere (validation) & 0.59 \\
\hline
\end{tabular}

ASPECTS, Alberta Stroke Program Early CT Score; mRS, modified Rankin Scale.

strated superior predictive power for functional outcomes (C-statistic 0.78) as compared to the original ASPECTS (C-statistic 0.67), but not for the left hemisphere, as shown in Table 3.

\section{Discussion}

In this study of 342 patients treated with EST, we examined the relative contributions of each ASPECTS subregion towards 90-day disability outcomes. The findings in our study demonstrate that ASPECTS regions contribute differentially towards clinical outcomes, and as such, patients with identical ASPECTS values but different regions of involvement may have dramatically different baseline injuries and responses to EST. With regards to functional outcomes, involvement of the high cortical regions (M4-M6 on the right hemisphere and M3, 
M5, and M6 on the left hemisphere) contributed substantially more towards greater disability as compared to involvement of deep structures. Our findings support the concept of considering not only the total number of ASPECTS regions involved when deciding on treating a patient with EST, but also the hemisphere and location of the involved regions.

Patients with lower ASPECTS on 24-h CT presented with greater NIHSS score at presentation, greater frequency of ICA occlusion, lower rates of TICI $2 b / 3$, and longer times from onset to recanalization. In adjusted ordinal regression analysis, ASPECTS subregions demonstrated wide variability in contributions to mRS disability scores at 90 days, with both regionto-region as well as hemisphere-to-hemisphere variability. Specifically, involvement of cortical regions was more strongly tied to higher mRS score than deep regions. Thus, the likelihood of benefit from revascularization of a patient with involvement of cortical regions may be less than that of a patient with deep involvement alone. In addition, involvement of the M3 region on the left hemisphere, but not the right, showed a strong trend towards greater disability, possibly representing language function. wASPECTS demonstrated improved discrimination in the derivation cohort as well as in independent validation for the right, but not left, hemisphere.

Many of the variables that we found to be associated with lower 24-h ASPECTS are consistent with increased stroke severity. NIHSS score, ICA occlusion, lower rates of complete reperfusion, and longer times from onset to recanalization have been associated with poor outcome $[19,20]$. Similarly, predictors of poor outcome are known to correlate with increased final infarct volume [21]. Additionally, there exists a strong correlation between baseline imaging parameters and 24- to 48-h infarct volumes [22]. Various post hoc exploratory analyses of the SWIFT PRIME [23] and ESCAPE [24] trials have demonstrated the 24- to 48-h infarct volumes as a strong predictor of 90 -day $\mathrm{mRS}$ score. However, laterality of the infarction was not observed to be a significant predictor for 90-day clinical outcomes [24].

Our findings that there is a differential influence on clinical outcomes for ASPECTS regions are consistent with prior studies. Phan et al. [12] evaluated the use of initial CT-ASPECTS subregions in a National Institute of Neurological Disorders and Stroke recombinant tissue plasminogen activator study cohort and observed that M6 involvement in elderly patients was associated with poor clinical outcomes. Similarly, Khan et al. [25] recently illustrated the involvement of either M3 or M6 as key predictors of poor outcome in patients with distal occlusion of M2 segments. However, these studies utilized pretreatment CT-ASPECTS and did not account for ischemic core expansion and final infarct volumes. In a small, single-center cohort, Rangaraju et al. [26] demonstrated left M4 and right M6 subregions on DWI-ASPECTS to be independently associated with 3-month clinical outcomes. We also noted the relative importance of the peri-rolandic M6 region in our cohort, which represents the relative eloquence of the primary motor cortex and adjacent subcortical white matter. Interestingly, subcortical structures including the internal capsule for both cerebral hemispheres were less strongly associated with disability outcomes. These results are similar to those of prior studies and may represent the difficulty associated with determinations of internal capsule viability on noncontrast head CT [12, 25, 27].

One of the large questions that remain unanswered regarding patient selection in EST is the suitability of EST for patients with large infarct cores at presentation. A recent subgroup analysis of MR CLEAN suggested that patients with ASPECTS 5-7 should be treated with intra-arterial therapy [11]. Compared to patients with ASPECTS 8-10, slightly fewer ASPECTS 5-7 patients had good functional outcomes, while an equivalent number demonstrated moderate functional outcomes. This study further suggested a heterogeneous effect with marginal absolute benefit for patients with ASPECTS 0-4. Similarly, the authors of IMS-III observed no interaction between ASPECTS ( $>8 \mathrm{vs.} \leq 7$ ) pertaining to intra-arterial treatment [28]. Interestingly, $21 \%$ of 92 patients with ASPECTS 0-4 had good functional outcome. Thus, 
while the frequency of good outcomes is lower in patients presenting with poorer ASPECTS, there remains a population that likely benefits.

In this study we derived a wASPECTS from parameter estimates of a multivariate regression and demonstrated improved discrimination for clinical outcomes on 24-h CT relative to the original ASPECTS. This wASPECTS could be used in clinical settings in several different ways. Most directly, the wASPECTS itself can be readily calculated as the weighting values are constant. Alternatively and more readily, however, the findings of the wASPECTS, which relay the relative importance of cortical regions compared to deeper territories, can be incorporated intuitively when interpreting CT images of stroke patients considered for EST.

Our study has some limitations. Although only high-volume stroke centers participated in the SWIFT, STAR, and SWIFT PRIME studies, our study was an exploratory subgroup analysis and is accompanied by the limitations of pooled post hoc analyses. Additionally, caution is warranted in utilization of our findings in the real world, given that all imaging was adjudicated to an independent core laboratory without the time pressures seen in acute settings. Additionally, for the majority of patients in our study, final infarct ASPECTS was determined by 24-h CT scan. CT at this time point may over- or underestimate the degree of infarction. A later scan or use of MRI in all patients may provide improved infarct visualization, though this would limit generalizability. In addition, while in clinical practice ASPECTS is used as an imaging parameter at the time of presentation, we chose to derive our models from 24-h CT imaging. This study design decision was made intentionally, as the final infarct will correlate more strongly with outcome than presentation CT imaging, in which not all areas of injuries are readily seen or have gone on to eventual injury.

In conclusion, we illustrate the wide variability in impact on 90-day disability outcomes across the different ASPECTS regions. For both right and left hemispheres, preservation of the high cortical regions was more strongly associated with improved outcomes compared to the deep regions. Our findings support taking into consideration not only the total ASPECTS, but also the location and relative weightings of the involved regions when evaluating a patient for EST.

\section{Acknowledgments}

The authors would like to thank Scott Brown for his help as the independent statistician in this study and Rachel Castro for her help in coordinating the work.

\section{Disclosure Statement}

Drs. Saver and Jahan have served as unpaid site investigators in multicenter trials run by Lundbeck and Covidien for which the UC Regents received payments on the basis of clinical trial contracts for the number of subjects enrolled. The University of California has patent rights in retrieval devices for stroke. Drs. Gralla and Pereira have served as site investigators and/or consultants for Covidien. Dr. Yoo reports research grants from Codman/Neuravi Inc. and Penumbra Inc. as well as equity ownership in Insera Therapeutics Inc. Dr. Nogueira reports travel support for activities related to the DAWN Trial. Drs. Sheth, Malhotra, Liebeskind, Liang, Albers, and Goyal report no disclosures.

\section{Funding Sources}

This study was sponsored in part by Medtronic (Dublin, Ireland) as well as by the American Heart Association (15CRP22900006; principal investigator: Dr. Sheth) and by the Society for Neurointerventional Surgery Foundation. 


\section{References}

1 Berkhemer OA, Fransen PS, Beumer D, van den Berg LA, Lingsma HF, Yoo AJ, Schonewille WJ, Vos JA, Nederkoorn PJ, Wermer MJ, van Walderveen MA, Staals J, Hofmeijer J, van Oostayen JA, Lycklama à Nijeholt GJ, Boiten J, Brouwer PA, Emmer BJ, de Bruijn SF, van Dijk LC, Kappelle LJ, Lo RH, van Dijk EJ, de Vries J, de Kort PL, van Rooij WJ, van den Berg JS, van Hasselt BA, Aerden LA, Dallinga RJ, Visser MC, Bot JC, Vroomen PC, Eshghi O, Schreuder TH, Heijboer RJ, Keizer K, Tielbeek AV, den Hertog HM, Gerrits DG, van den Berg-Vos RM, Karas GB, Steyerberg EW, Flach HZ, Marquering HA, Sprengers ME, Jenniskens SF, Beenen LF, van den Berg R, Koudstaal PJ, van Zwam WH, Roos YB, van der Lugt A, van Oostenbrugge RJ, Majoie CB, Dippel DW; MR CLEAN Investigators: A randomized trial of intraarterial treatment for acute ischemic stroke. N Engl J Med 2015;372: 11-20.

2 Campbell BC, Mitchell PJ, Kleinig TJ, Dewey HM, Churilov L, Yassi N, Yan B, Dowling RJ, Parsons MW, Oxley TJ, Wu TY, Brooks M, Simpson MA, Miteff F, Levi CR, Krause M, Harrington TJ, Faulder KC, Steinfort BS, Priglinger M, Ang T, Scroop R, Barber PA, McGuinness B, Wijeratne T, Phan TG, Chong W, Chandra RV, Bladin CF, Badve M, Rice H, de Villiers L, Ma H, Desmond PM, Donnan GA, Davis SM: Endovascular therapy for ischemic stroke with perfusion-imaging selection. N Engl J Med 2015;372:1009-1018.

3 Saver JL, Goyal M, Bonafe A, Diener HC, Levy EI, Pereira VM, Albers GW, Cognard C, Cohen DJ, Hacke W, Jansen O, Jovin TG, Mattle HP, Nogueira RG, Siddiqui AH, Yavagal DR, Baxter BW, Devlin TG, Lopes DK, Reddy VK, du Mesnil de Rochemont R, Singer OC, Jahan R: Stent-retriever thrombectomy after intravenous t-PA vs. t-PA alone in stroke. N Engl J Med 2015;372:2285-2295.

4 Jovin TG, Chamorro A, Cobo E, de Miquel MA, Molina CA, Rovira A, San Roman L, Serena J, Abilleira S, Ribo M, Millan M, Urra X, Cardona P, Lopez-Cancio E, Tomasello A, Castano C, Blasco J, Aja L, Dorado L, Quesada H, Rubiera M, Hernandez-Perez M, Goyal M, Demchuk AM, von Kummer R, Gallofre M, Davalos A: Thrombectomy within $8 \mathrm{~h}$ after symptom onset in ischemic stroke. N Engl J Med 2015;372:2296-2306.

5 Goyal M, Demchuk AM, Menon BK, Eesa M, Rempel JL, Thornton J, Roy D, Jovin TG, Willinsky RA, Sapkota BL, Dowlatshahi D, Frei DF, Kamal NR, Montanera WJ, Poppe AY, Ryckborst KJ, Silver FL, Shuaib A, Tampieri D, Williams D, Bang OY, Baxter BW, Burns PA, Choe H, Heo JH, Holmstedt CA, Jankowitz B, Kelly M, Linares G, Mandzia JL, Shankar J, Sohn SI, Swartz RH, Barber PA, Coutts SB, Smith EE, Morrish WF, Weill A, Subramaniam S, Mitha AP, Wong JH, Lowerison MW, Sajobi TT, Hill MD: Randomized assessment of rapid endovascular treatment of ischemic stroke. N Engl J Med 2015;372:1019-1030.

6 Broderick JP, Palesch YY, Demchuk AM, Yeatts SD, Khatri P, Hill MD, Jauch EC, Jovin TG, Yan B, Silver FL, von Kummer R, Molina CA, Demaerschalk BM, Budzik R, Clark WM, Zaidat OO, Malisch TW, Goyal M, Schonewille WJ, Mazighi M, Engelter ST, Anderson C, Spilker J, Carrozzella J, Ryckborst KJ, Janis LS, Martin RH, Foster LD, Tomsick TA: Endovascular therapy after intravenous t-PA versus t-PA alone for stroke. N Engl J Med 2013; 368:893-903.

7 Ciccone A, Valvassori L, Nichelatti M, Sgoifo A, Ponzio M, Sterzi R, Boccardi E: Endovascular treatment for acute ischemic stroke. N Engl J Med 2013;368:904-913.

8 Kidwell CS, Jahan R, Gornbein J, Alger JR, Nenov V, Ajani Z, Feng L, Meyer BC, Olson S, Schwamm LH, Yoo AJ, Marshall RS, Meyers PM, Yavagal DR, Wintermark M, Guzy J, Starkman S, Saver JL: A trial of imaging selection and endovascular treatment for ischemic stroke. N Engl J Med 2013;368:914-923.

9 Barber PA, Demchuk AM, Zhang J, Buchan AM: Validity and reliability of a quantitative computed tomography score in predicting outcome of hyperacute stroke before thrombolytic therapy. ASPECTS Study Group. Alberta Stroke Programme Early CT Score. Lancet 2000;355:1670-1674.

10 Powers WJ, Derdeyn CP, Biller J, Coffey CS, Hoh BL, Jauch EC, Johnston KC, Johnston SC, Khalessi AA, Kidwell CS, Meschia JF, Ovbiagele B, Yavagal DR: 2015 AHA/ASA Focused Update of the 2013 Guidelines for the Early Management of Patients with Acute Ischemic Stroke regarding Endovascular Treatment. A Guideline for Healthcare Professionals from the American Heart Association/American Stroke Association 2015.

11 Yoo AJ, Berkhemer OA, Fransen PSS, van den Berg LA, Beumer D, Lingsma HF, Schonewille WJ, Sprengers MES, van den Berg R, van Walderveen MAA, Beenen LFM, Wermer MJH, Nijeholt GJLÀ, Boiten J, Jenniskens SFM, Bot JCJ, Boers AMM, Marquering HA, Roos YBWEM, van Oostenbrugge RJ, Dippel DWJ, van der Lugt A, van Zwam WH, Majoie CBLM; MR CLEAN Investigators: Effect of baseline Alberta Stroke Program Early CT Score on safety and efficacy of intra-arterial treatment: a subgroup analysis of a randomised phase 3 trial (MR CLEAN). Lancet Neurol 2016;15:685-694.

12 Phan TG, Demchuk A, Srikanth V, Silver B, Patel SC, Barber PA, Levine SR, Hill MD: Proof of concept study: relating infarct location to stroke disability in the NINDS rt-PA trial. Cerebrovasc Dis 2013;35:560-565.

13 Cheng B, Forkert ND, Zavaglia M, Hilgetag CC, Golsari A, Siemonsen S, Fiehler J, Pedraza S, Puig J, Cho TH, Alawneh J, Baron JC, Ostergaard L, Gerloff C, Thomalla G: Influence of stroke infarct location on functional outcome measured by the modified Rankin Scale. Stroke 2014;45:1695-1702.

14 Gale SD, Pearson CM: Neuroimaging predictors of stroke outcome: implications for neurorehabilitation. NeuroRehabilitation 2012;31:331-344.

15 Menezes NM, Ay H, Wang Zhu M, Lopez CJ, Singhal AB, Karonen JO, Aronen HJ, Liu Y, Nuutinen J, Koroshetz WJ, Sorensen AG: The real estate factor: quantifying the impact of infarct location on stroke severity. Stroke 2007; 38:194-197.

16 Beloosesky Y, Streifler JY, Burstin A, Grinblat J: The importance of brain infarct size and location in predicting outcome after stroke. Age Ageing 1995;24:515-518. 
17 Saver JL, Jahan R, Levy EI, Jovin TG, Baxter B, Nogueira RG, Clark W, Budzik R, Zaidat O0: Solitaire Flow Restoration Device versus the Merci Retriever in patients with acute ischaemic stroke (SWIFT): a randomised, parallel-group, non-inferiority trial. Lancet 2012;380:1241-1249.

18 Pereira VM, Gralla J, Davalos A, Bonafe A, Castano C, Chapot R, Liebeskind DS, Nogueira RG, Arnold M, Sztajzel R, Liebig T, Goyal M, Besselmann M, Moreno A, Schroth G: Prospective, multicenter, single-arm study of mechanical thrombectomy using Solitaire Flow Restoration in acute ischemic stroke. Stroke 2013;44:28022807.

19 Yoo AJ, Romero J, Hakimelahi R, Nogueira RG, Rabinov JD, Pryor JC, Gonzalez RG, Hirsch JA, Schaefer PW: Predictors of functional outcome vary by the hemisphere of involvement in major ischemic stroke treated with intra-arterial therapy: a retrospective cohort study. BMC Neurol 2010;10:25.

20 Wechsler LR, Roberts R, Furlan AJ, Higashida RT, Dillon W, Roberts H, Rowley HA, Pettigrew LC, Callahan AS 3rd, Bruno A, Fayad P, Smith WS, Firszt CM, Schulz GA: Factors influencing outcome and treatment effect in PROACT II. Stroke 2003;34:1224-1229.

21 Zaidi SF, Aghaebrahim A, Urra X, Jumaa MA, Jankowitz B, Hammer M, Nogueira R, Horowitz M, Reddy V, Jovin TG: Final infarct volume is a stronger predictor of outcome than recanalization in patients with proximal middle cerebral artery occlusion treated with endovascular therapy. Stroke 2012;43:3238-3244.

22 Albers GW, Goyal M, Jahan R, Bonafe A, Diener HC, Levy EI, Pereira VM, Cognard C, Cohen DJ, Hacke W, Jansen O, Jovin TG, Mattle HP, Nogueira RG, Siddiqui AH, Yavagal DR, Baxter BW, Devlin TG, Lopes DK, Reddy VK, de Rochemont Rdu M, Singer OC, Bammer R, Saver JL: Ischemic core and hypoperfusion volumes predict infarct size in SWIFT PRIME. Ann Neurol 2016;79:76-89.

23 Albers GW, Goyal M, Jahan R, Bonafe A, Diener HC, Levy EI, Pereira VM, Cognard C, Yavagal DR, Saver JL: Relationships between imaging assessments and outcomes in Solitaire With the Intention for Thrombectomy as Primary Endovascular Treatment for Acute Ischemic Stroke. Stroke 2015;46:2786-2794.

24 Al-Ajlan FS, Goyal M, Demchuk AM, Minhas P, Sabiq F, Assis Z, Willinsky R, Montanera WJ, Rempel JL, Shuaib A, Thornton J, Williams D, Roy D, Poppe AY, Jovin TG, Sapkota BL, Baxter BW, Krings T, Silver FL, Frei DF, Fanale C, Tampieri D, Teitelbaum J, Lum C, Dowlatshahi D, Shankar JJ, Barber PA, Hill MD, Menon BK: Intraarterial therapy and post-treatment infarct volumes: insights from the ESCAPE randomized controlled trial. Stroke 2016;47:777-781.

25 Khan M, Baird GL, Goddeau RP Jr, Silver B, Henninger N: Alberta Stroke Program Early CT Score infarct location predicts outcome following M2 occlusion. Front Neurol 2017;8:98.

26 Rangaraju S, Streib C, Aghaebrahim A, Jadhav A, Frankel M, Jovin TG: Relationship between lesion topology and clinical outcome in anterior circulation large vessel occlusions. Stroke 2015;46:1787-1792.

27 Phan TG, Chen J, Donnan G, Srikanth V, Wood A, Reutens DC: Development of a new tool to correlate stroke outcome with infarct topography: a proof-of-concept study. Neuroimage 2010;49:127-133.

28 Hill MD, Demchuk AM, Goyal M, Jovin TG, Foster LD, Tomsick TA, von Kummer R, Yeatts SD, Palesch YY, Broderick JP: Alberta Stroke Program early computed tomography score to select patients for endovascular treatment: Interventional Management of Stroke (IMS)-III Trial. Stroke 2014;45:444-449. 